Supplementary information

\title{
Aerosol-phase synthesis and processing of luminescent silicon nanocrystals
}

\author{
Zhaohan Li and Uwe R. Kortshagen* \\ Department of Mechanical Engineering, University of Minnesota, Minneapolis, MN, 55455, \\ United States \\ *E-mail: kortshagen@umn.edu
}

\section{Supporting data}

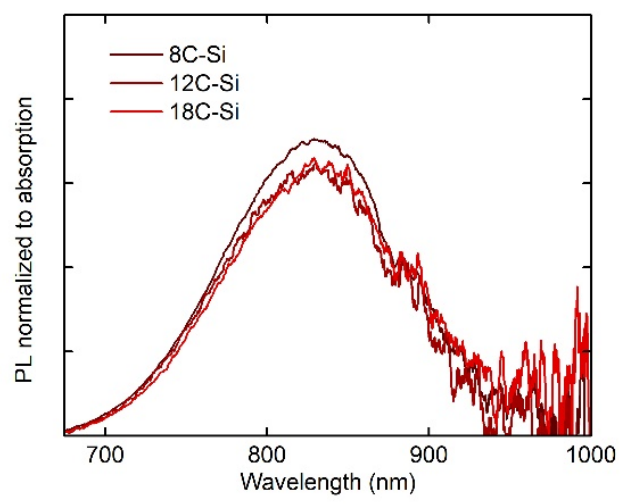

Figure S1. PL spectra of $3.2 \mathrm{~nm}$ Si NCs functionalized with 1-octene, 1-dodecene and 1-octadecene with the furnace temperature of $500^{\circ} \mathrm{C}$. 


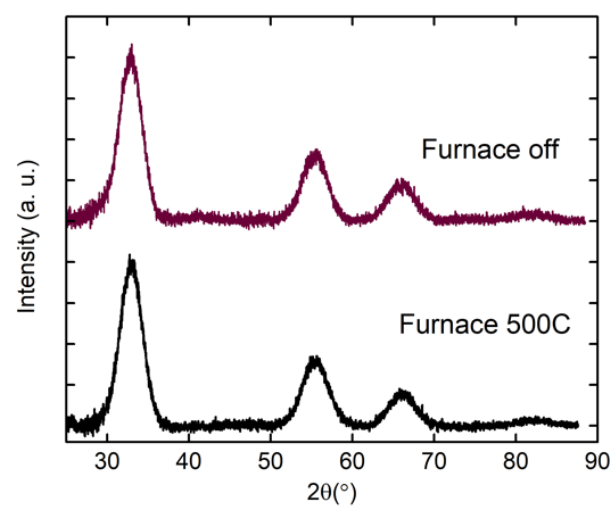

Figure S2. X-ray diffraction pattern for Si NCs with different furnace processing temperatures. Sizes from Scherrer fitting are $3.2 \mathrm{~nm}$ for both samples.

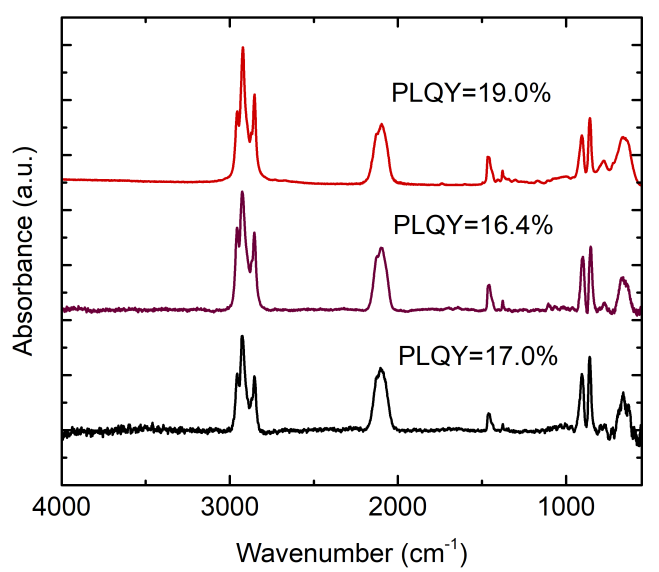

Figure S3. FTIR spectra of 1-octene functionalized Si NCs with different surface coverage. The peak between 3000 and $2800 \mathrm{~cm}^{-1}$ is attributed to $\mathrm{C}-\mathrm{H}$ stretching vibration. 


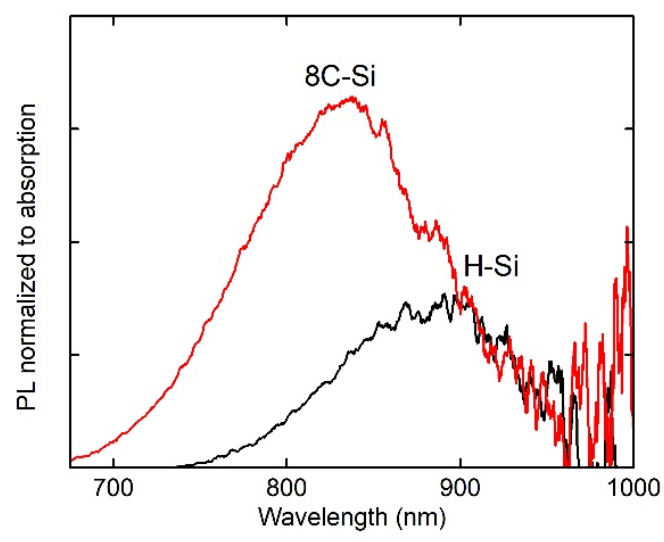

Figure S4. PL spectra of $3.2 \mathrm{~nm}$ diameter, non-functionalized and 1-octene functionalized Si NCs dispersed in toluene.

\section{Additional experimental details}

Reactor tube geometry. Argon and silane (5\% in helium) were flowed through a $3 / 8^{\prime \prime}$ borosilicate glass tube which expanded to 1 " with a sidearm port for ligand injection into the plasma afterglow region. The powered electrode was placed $2 \mathrm{~cm}$ above the sidearm position.

Ligand delivery. Ligands were delivered as vapors by flowing $100 \mathrm{sccm}$ hydrogen through a bubbler. Ligand feed rates were controlled by adjusting the bubbler pressure via a metering valve while keeping hydrogen flow rates constant. Table S1 lists the conditions to obtain surface ligand coverages of $25 \%-30 \%$ for 1 -octene, 1 -dodecene, and 1-octadecene.

Table S1. Functionalization conditions for different ligands and surface coverage. Surface coverage is estimated from $\mathrm{C}$ and $\mathrm{H}$ weight percentage using $\mathrm{CHN}$ elemental analysis.

\begin{tabular}{|c|c|c|c|c|c|}
\hline Ligand & $\begin{array}{c}\text { Ligand vapor } \\
\text { pressure } \\
\text { (Torr) }\end{array}$ & $\begin{array}{c}\text { Bubbler } \\
\text { pressure } \\
\text { (Torr) }\end{array}$ & $\begin{array}{c}\text { Ligand } \\
\text { consumption }\end{array}$ & $\begin{array}{c}\text { Ligand mass } \\
\text { percent } \\
(\%)\end{array}$ & $\begin{array}{c}\text { Surface coverage } \\
(\%)\end{array}$ \\
\hline 1-octene & 17.4 & 100 & $>1 \mathrm{~mL} /$ hour & 23.3 & 25 \\
\hline 1-dodecene & 0.52 & 33 & $<0.5 \mathrm{~mL} / \mathrm{hour}$ & 32.8 & 26 \\
\hline $\begin{array}{c}\text { 1-octadecene } \\
\left(140^{\circ} \mathrm{C}\right)\end{array}$ & & 35 & $<0.5 \mathrm{~mL} /$ hour & 43.9 & 28 \\
\hline
\end{tabular}


Si NC collection. The Si NCs were collected via inertial impaction onto glass substrates. A rectangular slit orifice was used to accelerate the aerosol stream containing Si NCs. For the three conditions listed in Table 1 , three different width slit orifices were used $\left(0.025^{\prime \prime}, 0.035^{\prime \prime}, 0.05^{\prime \prime}\right)$ to maintain the pressure of the plasma synthesis region at $2.2-2.4$ Torr. The pressure downstream the orifice was around 0.5 Torr. A glass substrate was mounted onto a pushrod assembly (Figure S5) and placed $\sim 5 \mathrm{~mm}$ beneath the slit orifice to collect the Si NCs. The pushrod assembly allowed air-free transfer of the Si NCs into a nitrogen-filled glovebox after synthesis.

The reactor can be continuously operated for a few hours. Silicon nanoparticle production rates were measured by measuring the weight of collected silicon nanoparticles. With $0.7 \mathrm{sccm} \mathrm{of} \mathrm{SiH}_{4}$, $5.3 \mathrm{mg}$ of $3.2 \mathrm{~nm}$ diameter, 1-octene functionalized silicon nanocrystals were collected over 30 minutes. As the ligand mass is measured to be $32 \%$ of total mass from thermalgravimetric measurements, this collection rate corresponds to a silicon conversion rate of $\sim 14 \%$. Compared with previous production rates of Si NCs of the same size from the Kortshagen group (14.4 mg/h with $0.4 \mathrm{sccm} \mathrm{SiH}_{4}$ flow), the lower Si conversion efficiency here is likely due to enhanced losses of Si NCs to the reactor walls during the in-flight furnace heating.

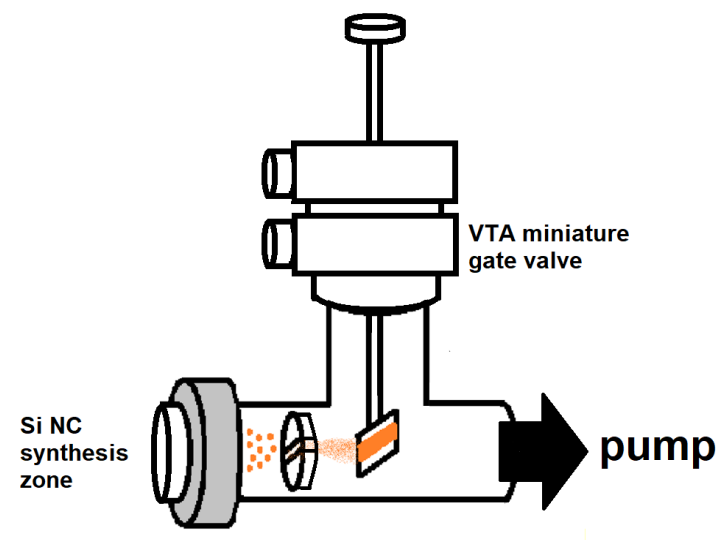

Figure S5. Schematic of the impaction orifice and the pushrod assembly. After nanocrystal collection, the reactor was filled with argon to atmospheric pressure. The VAT miniature gate valves were then closed, allowing the samples to be sealed in argon during transfer. 